\title{
HUBUNGAN EFIKASI DIRI DENGAN KETERIKATAN KERJA PADA GURU DI SEKOLAH INKLUSI DI JAKARTA
}

\author{
Nathania Tanurezal ${ }^{1}$, Raja Oloan Tumanggor ${ }^{2}$
}

\author{
1Program Studi Sarjana Psikologi, Universitas Tarumanagara, Jakarta \\ Email: nathanianat@gmail.com \\ 2 Fakultas Psikologi, Universitas Tarumanagara, Jakarta \\ Email: rajat@fpsi.untar.ac.id
}

Masuk : 14-07-2020, revisi: 25-10-2020, diterima untuk diterbitkan : 31-10-2020

\begin{abstract}
Profession as class teacher in inclusive schools is not an easy profession, especially if the teacher lacks the required competencies. Lack of competence can affect self-efficacy associated with work engagement to classroom teachers. Self-efficacy is one's belief in one's ability to complete a task or goal and to produce the desired positive effect.Meanwhile, work engagement is defined as a positive work attitude and performance that can improve overall company performance.This study aims to determine whether there is a positive relationship between self efficacy and work engagement to classroom teachers in inclusive schools. This research is a nonexperimental quantitative research that tests the correlation between two variables using convenience sampling techniques. The measuring instrument used was a self-efficacy scale developed by Jerusalem and Schwarzer, and a work engagement scale developed by Schaufeli, González-Romá, and Bakker. The subjects in this study were 34 class teachers in inclusive schools in Jakarta. The results of the analysis using the Pearson correlation test have the results of $r=0.459, p=0.006<0.05$, so it can be concluded that self efficacy has a significant positive relationship with work engagement to class teachers in inclusive schools. Then it can be said that the higher the self efficacy is, the higher the work engagement will be. Vice versa, the lower the self efficacy is, the lower the work engagement will be.
\end{abstract}

Keywords: self efficacy, work engagement, teacher, inclusive school

\begin{abstract}
ABSTRAK
Profesi guru kelas di sekolah inklusi bukanlah profesi yang mudah, terutama apabila guru kurang memiliki kompetensi yang dibutuhkan. Kurangnya kompetensi dapat mempengaruhi efikasi diri yang dikaitkan dengan keterikatan kerja pada guru kelas. Efikasi diri merupakan keyakinan seseorang atas kemampuan yang dimiliki oleh seseorang agar dapat menyelesaikan suatu tugas atau tujuan dan dapat menghasilkan efek positif yang diinginkan. Sementara keterikatan kerja adalah Keterikatan kerja didefinisikan sebagai sikap dan performa kerja positif yang dapat meningkatkan performa perusahaan secara keseluruhan. Penelitian ini bertujuan untuk mengetahui apakah terdapat hubungan positif antara efikasi diri dengan keterikatan kerja pada guru kelas di sekolah inklusi. Penelitian ini merupakan penelitian kuantitatif non eksperimental yang menguji korelasi antar dua variabel dengan menggunakan teknik convenience sampling. Alat ukur yang digunakan adalah Skala Efikasi Diri yang dikembangkan oleh Jerusalem dan Schwarzer, serta Skala Keterikatan Kerja yang dikembangkan Schaufeli, González-Romá, dan Bakker. Subyek pada penelitian ini merupakan 34 orang guru kelas di sekolah inklusi di Jakarta. Hasil analisis menggunakan uji korelasi Pearson memiliki hasil $r=0.459, p$ $=0.006<0.05$, sehingga dapat disimpulkan bahwa efikasi diri memiliki hubungan positif yang signifikan dengan keterikatan kerja pada guru kelas di sekolah inklusi. Maka dapat dikatakan bahwa semakin tinggi efikasi diri, maka akan semakin tinggi keterikatan kerja. Demikian juga sebaliknya, semakin rendah efikasi diri, maka semakin rendah juga keterikatan kerja.
\end{abstract}

Kata Kunci: efikasi diri, keterikatan kerja, guru, sekolah inklusi

\section{PENDAHULUAN \\ Latar Belakang}

Menurut data Badan Pusat Statistik (BPS) pada tahun 2017, jumlah Anak Berkebutuhan Khusus (ABK) di Indonesia mencapai angka 1,6 juta anak (Kemdikbud, 2017). Salah satu upaya pemerintah untuk memberikan layanan pendidikan bagi ABK adalah dengan 
membangun sekolah inklusi. Sekolah inklusi adalah layanan pendidikan yang memberikan kesempatan kepada ABK untuk mengikuti proses pembelajaran dalam satu lingkungan pendidikan yang sama dengan peserta didik pada umumnya (Sulistyadi, 2014). Layanan pendidikan disesuaikan dengan kebutuhan peserta didik, dari segi kompetensi, kurikulum, metode belajar, penilaian, dan sarana prasarana. Sekolah inklusi bertujuan untuk merangkul semua peserta didik yang memiliki latar belakang dan kebutuhan beragam sehingga dapat memperoleh pendidikan yang layak dan setara tanpa adanya diskriminasi, supaya dapat berkembang selaras dan seimbang, sama seperti peserta didik normal lainnya (Kadir, 2015).

Idealnya, pada satu kelas di sekolah inklusi terdapat minimal satu Guru Pendamping Khusus (GPK) dan satu guru kelas. GPK merupakan guru dari lulusan Pendidikan Luar Biasa, sedangkan guru dari lulusan guru biasa. GPK bertugas mendampingi ABK belajar di kelas, sedangkan guru kelas bertugas untuk mengajar di depan kelas. Karena adanya kesenjangan jumlah dan kurangnya GPK, pada akhirnya guru kelas yang harus mengajar dan mendampingi $\mathrm{ABK}$ di sekolah inklusi.

Guru kelas belum siap menangani anak-anak berkebutuhan khusus karena tidak memiliki kompetensi khusus dalam mengajar ABK. Guru kelas mengeluh merasa kesulitan dalam mengajar dan waktunya banyak tersita karena harus mengajar satu metode ke murid dengan karakteristik yang berbeda (TribunJogja, 2018). Hal tersebut juga menyebabkan terdapat guru yang terlihat terpaksa dalam mengajar dan mendampingi anak berkebutuhan khusus di kelas (Rombot, 2017). Guru kelas yang tidak memiliki kompetensi dan pengalaman mungkin akan mempengaruhi keyakinan guru terhadap kemampuannya sendiri, yang biasanya disebut sebagai efikasi diri. Terdapat beberapa guru yang masih merasa tidak yakin dengan kemampuannya, meskipun telah dibekali pelatihan dan seminar (Prastadila \& Pramita, 2013). Juga terdapat guru dengan efikasi diri yang rendah dan tidak yakin mampu mengajar ABK di sekolah inklusi (Shade \& Stewart; Gallis \& Tanner dalam Prastadila \& Pramita, 2013).

Menurut Bandura dalam Feist \& Feist (2009), efikasi diri didefinisikan sebagai "kepercayaan seseorang atas kemampuan dirinya untuk mengontrol atas fungsi diri sendiri dan keadaan lingkungan" (h.488). Efikasi diri merupakan keyakinan seseorang atas kemampuan yang dimiliki oleh seseorang agar dapat menyelesaikan suatu tugas atau tujuan dan dapat menghasilkan efek positif yang diinginkan (Feist \& Feist, 2009; King, 2014).

Bandura (1997) menjelaskan bahwa efikasi diri ditandai dengan tiga dimensi, yaitu (a) level merupakan keyakinan individu terhadap dirinya yang berhubungan dengan derajat kesulitan dan tantangan yang terdapat dalam suatu tugas. Keyakinan seseorang untuk sukses dalam suatu tugas biasanya dapat diukur melalui tingkat tuntutan tugas yang merepresentasikan berbagai tingkat kesulitan dan tantangan dari tugas, atau hambatan yang dapat menghambat seseorang untuk sukses. Jika tidak terdapat hambatan dalam suatu tugas, maka tugas tersebut akan mudah untuk dikerjakan. Hal tersebut mengakibatkan setiap individu akan memiliki keseragaman tingkat self efficacy yang tinggi terhadap tugas tersebut. Maka, semakin sulit suatu tugas, tingkat self efficacy individu akan cenderung menurun sesuai dengan tingkat kesulitas tugas. Dimensi kedua, (b) generality, adalah tingkat keyakinan individu dalam melakukan berbagai tugas yang bervariasi. Dimensi ketiga, (c) strength, adalah keyakinan individu terhadap kemampuan dirinya dalam mengerjakan tugas. 
Namun, terdapat guru kelas yang tidak memiliki kompetensi tetapi bersemangat dan rela berkorban untuk mengajar ABK. Seperti yang ditunjukkan oleh Heni Handayani di SDN Bojongherang. Walaupun Heni bukan berasal dari lulusan Pendidikan Luar Biasa, Heni mengajar 21 siswa ABK tanpa digaji, bahkan rela menjual ikan asin dan kerudung untuk mendukung biaya operasional sekolah (PojokJabar.com, 2018). Selain itu, Mananta Adi Wijaya merupakan satu- satunya GPK yang bekerja di Sekolah Kramat Jati 01 pagi dan sudah mengajar selama 5 tahun. Namun, Adi tetap bersemangat dalam mengajar anak-anak berkebutuhan khusus walaupun hanya mengajar sendirian (JawaPos.com, 2017). Terdapat guru yang menunjukkan memiliki tingkat keterikatan kerja yang tinggi.

Keterikatan kerja didefinisikan sebagai sikap dan performa kerja positif yang dapat meningkatkan performa perusahaan secara keseluruhan (Sonnentag dalam Lu, Lu, Gursoy, \& Neale, 2015). Bakker dan Leiter (2010) mengemukakan bahwa keterikatan kerja ditandai dengan adanya tiga dimensi, yaitu (a) vigor atau semangat, yaitu adanya semangat dan energi yang tinggi saat bekerja, memiliki daya tahan saat bekerja ketika menemukan kesulitan, keinginan untuk menaruh usaha yang maksimal pada pekerjaannya, dan ketekunan untuk bekerja walaupun dihadapkan pada tantangan. Keinginan individu untuk memberikan hasil dan usaha yang maksimal ketika dihadapkan dengan masalah serta tantangan dalam bekerja menunjukkan bahwa individu tersebut memiliki dimensi vigor yang cukup baik. Dimensi kedua, (b) dedication atau dedikasi, yaitu ikut turut serta ke dalam pekerjaan, dan mengalami identifikasi yang kuat mengenai semangat bekerja, inspirasi, kebanggaan, dan tantangan. Dedication memiliki pengertian yang lebih luas, yang tidak hanya merujuk pada kognitif dan kepercayaan seseorang, tetapi mencakup dimensi afektif juga (Schaufeli et al., 2002). Dimensi terakhir, (c) absorption atau penyerapan, yaitu ditandai dengan kebahagiaan dan tingkat konsentrasi yang tinggi saat bekerja, tidak merasakan bahwa waktu telah berlalu ketika sedang bekerja, dan kesulitan melepaskan diri dari pekerjaan. Individu yang melakukan pekerjaannya dengan bahagia mungkin akan merasa tenggelam dalam pekerjaannya. Individu tersebut benar-benar telah terlibat dalam pekerjaannya dan mungkin akan merasa waktu berlalu dengan cepat dan merasa kesulitan untuk melepaskan diri dari pekerjaannya.

Terdapat penelitian terdahulu yang menyatakan bahwa keterikatan kerja berkaitan dengan efikasi diri. Seperti yang tertulis di penelitian oleh Simbula, Guglielmi, dan Schaufeli pada tahun 2011, yang salah satunya meneliti hubungan efikasi diri terhadap keterikatan kerja dengan subyek guru Itali. Untuk membuktikan hipotesis pada penelitian tersebut yang menyatakan bahwa efikasi diri memiliki efek positif terhadap keterikatan kerja. Pada penelitian tersebut, dilakukan pengujian hipotesis dengan cara studi panel 3 gelombang dengan jeda waktu 4 bulan bagi setiap panel. Studi panel adalah jenis penelitian yang dilakukan dalam waktu yang berlainan, namun tetap menggunakan sampel yang sama. Panel pertama yaitu pada awal tahun akademik, panel kedua pada akhir semester pertama, dan panel ketiga pada akhir tahun akademik. Hasilnya terdapat hubungan positif dari efikasi diri dengan keterikatan kerja, walaupun hanya terjadi pada 1 dari 3 panel penelitian tersebut. Jadi, hanya terdapat sebagian dukungan bagi hipotesis tersebut.

Berdasarkan fenomena yang telah dijelaskan diatas, dapat disimpulkan bahwa terdapat guru kelas di sekolah inklusi yang tidak memiliki kompetensi, namun menunjukkan keterikatan kerja yang cukup tinggi dengan pekerjaannya. Dengan adanya fenomena tersebut, peneliti ingin meneliti apakah terdapat hubungan positif antara efikasi diri dengan keterikatan kerja, 
khususnya pada guru kelas yang mengajar di sekolah inklusi.

Rumusan masalah pada penelitian ini adalah "Apakah efikasi diri berhubungan dengan keterikatan kerja pada guru kelas di sekolah inklusi?

\section{METODE PENELITIAN}

Penelitian ini menggunakan teknik convenience sampling atau yang bisa disebut juga sebagai teknik sampling insidental. Teknik sampling insidental merupakan teknik pengambilan sampel kepada siapa saja yang secara tidak sengaja bertemu dengan peneliti dan memiliki kriteria subyek yang cocok dan dapat digunakan sebagai sumber data (Sugiyono, 2017). Baley dalam Lestari (2014, h. 66) mengemukakan bahwa untuk penelitian yang menggunakan analisis data statistik, ukuran sampel paling minimum adalah 30 . Ukuran sampel dikatakan layak untuk penelitian jika jumlahnya 30 hingga 500 (Roscoe dalam Sugiyono, 2017). Subyek pada penelitian ini berjumlah 34 orang guru kelas yang mengajar di sekolah inklusi di Jakarta.

Pengukuran variabel efikasi diri menggunakan alat ukur General Self-Efficacy Scale (GSES) yang dikembangkan oleh Jerusalem dan Schwarzer pada tahun 1995. Alat ukur tersebut mengukur tiga dimensi dari efikasi diri, yaitu level, generality, dan strength. GSES terdiri dari 10 nomor pernyataan yang terdiri dari 3 nomor untuk dimensi level, 3 nomor untuk dimensi generality dan 4 nomor untuk dimensi strength. Kuesioner dari alat ukur ini menggunakan skala likert dengan 4 kategori jawaban. Kuesioner ini juga terdiri dari 9 nomor pernyataan positif dan 1 nomor pernyataan negatif.

Pengukuran variabel keterikatan kerja menggunakan alat ukur Utrecht Work Engagement Scale (UWES) yang dikembangkan Schaufeli, González-Romá, dan Bakker pada tahun 2002. Alat ukur tersebut mengukur tiga dimensi dari keterikatan kerja, yaitu vigor, dedication, dan absorption. UWES terdiri dari 17 nomor pernyataan yang terdiri dari 7 nomor untuk dimensi vigor, 4 nomor untuk dimensi dedication, dan 6 nomor untuk dimensi absorption. Kuesioner dari alat ukur UWES menggunakan skala likert dengan 6 kategori jawaban yang terdiri dari 17 nomor pernyataan positif.

\section{HASIL DAN PEMBAHASAN}

\section{Hasil}

Efikasi diri diukur menggunakan kuesioner dari alat ukur GSES untuk mendapatkan gambaran data dengan cara membandingkan mean empirik dengan mean hipotetik. Mean hipotetik pada variabel efikasi diri sebesar 2.5. Jika nilai mean empirik lebih besar daripada mean hipotetik, maka dapat dikatakan bahwa variabel atau dimensi tersebut memiliki nilai yang tinggi, demikian juga sebaliknya. Tabel 1 menunjukkan gambaran data efikasi diri. Tabel 1. Gambaran Data Efikasi Diri dan Dimensinya

\begin{tabular}{lcccccc}
\hline & N & $\begin{array}{c}\text { Mini } \\
\text { mum }\end{array}$ & $\begin{array}{c}\text { Maksi } \\
\text { mum }\end{array}$ & $\begin{array}{c}\text { Mean } \\
\text { Empirik }\end{array}$ & $\begin{array}{c}\text { Standar } \\
\text { Deviasi }\end{array}$ & Keterangan \\
\hline Efikasi diri & 34 & 21 & 36 & 30.09 & 3.769 & Tinggi \\
\hline $\begin{array}{l}\text { Dimensi } \\
\text { level }\end{array}$ & 34 & 7 & 12 & 10.09 & 1.422 & Tinggi \\
\hline $\begin{array}{l}\text { Dimensi } \\
\text { generality }\end{array}$ & 34 & 7 & 12 & 9.53 & 1.482 & Tinggi \\
\hline $\begin{array}{l}\text { Dimensi } \\
\text { strength }\end{array}$ & 34 & 7 & 12 & 10.47 & 1.398 & Tinggi \\
\hline
\end{tabular}


Keterikatan kerja diukur menggunakan kuesioner dari alat ukur UWES dan memiliki mean hipotetik sebesar 3.5. Jika nilai mean empirik lebih besar daripada mean hipotetik, maka dapat dikatakan bahwa variabel atau dimensi tersebut memiliki nilai yang tinggi, demikian juga sebaliknya. Tabel 2 menunjukkan gambaran data keterikatan kerja.

Tabel 2. Gambaran Data Keterikatan Kerja dan Dimensinya

\begin{tabular}{lcccccc}
\hline & N & $\begin{array}{c}\text { Mini } \\
\text { mum }\end{array}$ & $\begin{array}{c}\text { Maksi } \\
\text { mum }\end{array}$ & $\begin{array}{c}\text { Mean } \\
\text { Empirik }\end{array}$ & $\begin{array}{c}\text { Standar } \\
\text { Deviasi }\end{array}$ & Keterangan \\
\hline $\begin{array}{l}\text { Keterikatan } \\
\text { kerja }\end{array}$ & 34 & 63 & 96 & 85.65 & 7.827 & Tinggi \\
\hline $\begin{array}{l}\text { Dimensi } \\
\text { vigor }\end{array}$ & 34 & 26 & 42 & 35.91 & 4.115 & Tinggi \\
\hline $\begin{array}{l}\text { Dimensi } \\
\text { dedication }\end{array}$ & 34 & 16 & 24 & 22.03 & 2.355 & Tinggi \\
\hline $\begin{array}{l}\text { Dimensi } \\
\text { absorption }\end{array}$ & 34 & 20 & 35 & 30.53 & 3.457 & Tinggi \\
\hline
\end{tabular}

Uji normalitas dilakukan untuk mengetahui apakah sebuah data telah terdistribusi dengan normal atau tidak. Selain itu, uji normalitas juga dilakukan untuk menentukan teknik analisis data parametrik atau non parametrik. Data telah terdistribusi dengan normal apabila nilai $p$ lebih besar dari 0.05 (Nisfiannoor, 2013). Hasil uji normalitas variabel efikasi diri memiliki nilai $p 0.200>0.05$, sedangkan variabel keterikatan kerja memiliki nilai $p 0.058>$ 0.05. Maka dapat disimpulkan bahwa kedua variabel telah terdistribusi dengan normal.

Oleh karena kedua variabel telah terdistribusi dengan normal, maka pengujian korelasi menggunakan teknik korelasi parametrik yaitu korelasi Pearson. Hasil uji korelasi antara efikasi diri dengan keterikatan kerja memiliki nilai $r$ sebesar 0.459 dan nilai $p$ sebesar 0.006 . Nilai $r$ hitung bernilai positif dan lebih besar dari $r$ tabel (0.339), serta nilai $p$ lebih kecil dari 0.05. Berdasarkan hasil tersebut, maka dapat disimpulkan bahwa terdapat hubungan positif yang signifikan antara efikasi diri dengan keterikatan kerja.

Tabel 3. Hasil Uji Korelasi Efikasi Diri Dengan Keterikatan Kerja

\begin{tabular}{lccc}
\hline & & Keterikatan kerja & Keterangan \\
\hline Efikasi diri & $r$ & 0.459 & Terdapat hubungan positif \\
& & 0.006 & \\
& $p$ & & \\
\hline
\end{tabular}

Dilakukan juga analisis data tambahan berupa uji korelasi antara efikasi diri dengan dimensidimensi keterikatan kerja. Hasil uji korelasi efikasi diri dengan dimensi vigor memiliki nilai $r$ sebesar $0.485>r$ tabel 0.339 dan nilai $p$ sebesar $0.004<0.05$. Hasil uji korelasi efikasi diri dengan dimensi dedication memiliki nilai $r$ sebesar $0.345>r$ tabel 0.339 dan nilai $p$ sebesar $0.046<0.05$. Hasil uji korelasi efikasi diri dengan dimensi absorption memiliki nilai $r$ sebesar $0.461>r$ tabel 0.339 dan nilai $p$ sebesar $0.006<0.05$. Berdasarkan hasil tersebut, maka dapat disimpulkan bahwa terdapat hubungan positif yang signifikan antara efikasi diri dengan dimensi- dimensi keterikatan kerja. 


\begin{tabular}{|c|c|c|c|}
\hline & $R$ & $p$ & Keterangan \\
\hline $\begin{array}{l}\text { Efikasi diri } \\
\text { dengan } \\
\text { dimensi vigor }\end{array}$ & $\begin{array}{c}0.4 \\
85\end{array}$ & 0.004 & $\begin{array}{c}\text { Terdapat } \\
\text { hubungan } \\
\text { positif }\end{array}$ \\
\hline $\begin{array}{l}\text { Efikasi diri } \\
\text { dengan } \\
\text { dimensi } \\
\text { dedication }\end{array}$ & $\begin{array}{l}0.3 \\
45\end{array}$ & 0.046 & $\begin{array}{l}\text { Terdapat } \\
\text { hubungan } \\
\text { positif }\end{array}$ \\
\hline $\begin{array}{l}\text { Efikasi diri } \\
\text { dengan } \\
\text { dimensi } \\
\text { absorption }\end{array}$ & $\begin{array}{c}0.4 \\
61\end{array}$ & 0.006 & $\begin{array}{c}\text { Terdapat } \\
\text { hubungan } \\
\text { positif }\end{array}$ \\
\hline
\end{tabular}

\section{Pembahasan}

Berdasarkan analisa data utama dan tambahan, diketahui bahwa efikasi diri memiliki hubungan positif yang signifikan dengan keterikatan kerja. Apabila efikasi diri tinggi, maka keterikatan kerja juga akan tinggi. Demikian juga sebaliknya, apabila efikasi diri rendah, maka keterikatan kerja juga akan rendah. Diketahui juga bahwa efikasi diri memiliki hubungan positif dengan dimensi- dimensi keterikatan kerja.

Individu yang memiliki efikasi diri yang tinggi, akan merasa percaya diri dan yakin dapat mencapai kesuksesan dan menghadapi tantangan dalam hidup. Individu yang memiliki efikasi diri yang baik adalah memiliki performa yang baik dalam menghadapi kesulitan dalam suatu tugas (terkait dengan dimensi level), respon yang efektif terhadap suatu situasi yang bervariasi (terkait dengan dimensi generality), serta tekun dan gigih dalam menghadapi tantangan (terkait dengan dimensi strength).

Profesi sebagai guru, terutama guru yang bekerja di sekolah inklusi bukanlah profesi yang mudah. Peserta didik yang beragam, ABK dan normal, membutuhkan perhatian dan tenaga lebih. Profesi sebagai guru kelas di sekolah inklusi membutuhkan efikasi diri yang baik. Terdapat beberapa bukti bahwa guru tidak yakin dan kesulitan dalam mengajar ABK. Namun, terdapat bukti juga bahwa ada guru yang semangat dan menunjukkan tingkat keterikatan kerja yang tinggi dalam mengajar. Individu yang memiliki keterikatan kerja yang tinggi memiliki sikap dan performa kerja positif. Ciri-ciri individu yang memiliki keterikatan kerja yang tinggi adalah memiliki energi yang tinggi, keinginan untuk berusaha, dan gigih dalam menghadapi tantangan dalam bekerja (terkait dengan dimensi vigor); terlibat ke dalam pekerjaan dan memiliki rasa antusias dan bangga (terkait dengan dimensi dedication); serta nyaman dengan pekerjaannya sehingga tidak merasa bahwa waktu telah lewat dengan cepat dan kesulitan memisahkan diri dengan pekerjaannya (terkait dengan dimensi absorption).

Penelitian ini menemukan bahwa tingkat efikasi diri pada subyek cukup tinggi, terbukti dari nilai mean empirik yang lebih besar dari mean hipotetik $(30.09>2.5)$. Dari hasil tersebut, dapat dikatakan bahwa kendati guru kelas tidak memiliki pendidikan khusus untuk mengajar $\mathrm{ABK}$, tetapi merasa kompeten dan merasa yakin dapat mencapai kesuksesan sehingga mempengaruhi tingkat efikasi diri. Terdapat faktor sumber yang membentuk dan mempengaruhi tingkat efikasi diri guru yang tinggi, seperti kesuksesan yang berhasil diraih di masa lampau, adanya individu lain yang dijadikan model dan sumber motivasi untuk 
mencapai kesuksesan, adanya individu lain yang memberikan persuasi, serta adanya informasi somatik yang disampaikan oleh keadaan fisik dan emosional (Feist \& Feist, 2009).

Subyek juga memiliki tingkat keterikatan kerja yang cukup tinggi, terbukti dari jumlah mean empirik yang lebih besar daripada mean hipotetik $(85.65>3.5)$. Artinya guru yang 34 orang itu terikat dengan pekerjaannya tampak dari kegigihan, keinginan berusaha, dan nyaman dengan pekerjaannya. Terdapat faktor yang mempengaruhi tingginya tingkat keterikatan kerja, seperti tuntutan pekerjaan dan sumber daya pekerjaan (Demerouti et al. dalam Bakker \& Leiter, 2010). Serta terdapat faktor sumber daya pribadi yang mempengaruhi keterikatan kerja (Hobfoll et al. dalam Schaufeli, 2011).

Nilai koefisien korelasi yang berkisar dari 0.00 hingga 0.199 berarti hubungan sangat lemah (Sugiyono, 2017). Nilai koefisien korelasi $(p=0.006)$ memiliki arti bahwa hubungan antara efikasi diri dan keterikatan kerja. Penemuan ini juga sejalan dengan penelitian terdahulu yang dilakukan oleh Simbula, Guglielmi, dan Schaufeli pada tahun 2011, bahwa hanya terdapat dukungan sebagian bagi hipotesis penelitian yang menyatakan bahwa terdapat hubungan positif antara efikasi diri dengan keterikatan kerja.

\section{KESIMPULAN DAN SARAN}

Dari hasil analisis dan pembahasan yang telah dijabarkan diatas, dapat disimpulkan bahwa hipotesis penelitian diterima. Terdapat hubungan positif yang signifikan antara efikasi diri dan keterikatan kerja. Maka dapat dikatakan bahwa apabila efikasi diri tinggi, maka keterikatan kerja akan tinggi juga. Demikian juga sebaliknya, apabila efikasi diri rendah, maka keterikatan kerja akan rendah juga.

Penelitian ini diharapkan dapat memberikan kontribusi dan manfaat secara teoretis yang terkait dengan bidang psikologi industri dan organisasi, serta psikologi pendidikan. Penelitian ini juga diharapkan dapat menambah kajian teori untuk kedua variabel penelitian, yaitu efikasi diri dan keterikatan kerja. Penelitian selanjutnya dapat mempertimbangkan untuk menambah jumlah sampel menjadi lebih besar agar sampel lebih menggambarkan keseluruhan populasi.

Selain itu, penelitian selanjutnya juga dapat mempertimbangkan untuk menambah kriteria subyek penelitian, seperti masa bekerja guru agar gambaran subyek penelitian lebih bervariasi dan representatif.

Selain itu, terdapat juga saran untuk pihak sekolah yaitu untuk mengadakan pelatihanpelatihan yang dapat mendukung guru agar tingkat efikasi diri lebih meningkat. Pihak sekolah juga dapat mengadakan sharing group agar guru dapat menyampaikan keluh kesah dan kesulitan yang dialami saat mengajar. Upaya-upaya tersebut diharapkan dapat meningkatkan efikasi diri dan keterikatan kerja guru kelas yang mengajar di sekolah inklusi.

\section{Ucapan Terima Kasih (Acknowledgement)}

Peneliti mengucapkan terima kasih kepada seluruh pihak yang tidak dapat disebutkan satu persatu yang telah berkontribusi dalam proses penelitian ini dari awal hingga akhir. Peneliti sangat menghargai dukungan dan usaha yang diberikan kepada peneliti. 


\section{REFERENSI}

Bakker, A. B., \& Leiter, M. P. (2010). Work engagement a handbook of essential theory and research. New York: Psychology Press

Bandura, A. (1997). Self-efficacy: the exercise of control. New York: W. H. Freeman and Company

Feist, J., \& Feist, G. J. (2009). Theories of personality. Singapore: McGraw-Hill

JawaPos.com. (2017). Guru pendamping khusus ABK tetap semangat di tengah minimnya SDM. https://www.jawapos.com/nasional/pendidikan/18/07/2017/guru- pendampingkhusus-abk-tetap-semangat-di-tengah-minimnya-sdm/

Kadir, A. (2015). Penyelenggaraan sekolah inklusi di indonesia. Jurnal Pendidikan Agama Islam, 3(1), 1-22. doi: https://doi.org/10.15642/jpai.2015.3.1.1-22

Kementerian Pendidikan dan Kebudayaan. (2017). Sekolah inklusi dan pembangunan SLB dukung pendidikan inklusi. https://www.kemdikbud.go.id/main/blog/2017/02/ sekolah-inklusi-dan-pembangunan-slb- dukung-pendidikan-inklusi

King, L. A. (2014). The science of psychology. United States of America: McGraw-Hill

Lestari, R. A. (2014). Pengaruh kepemimpinan partisipatif dan komitmen organisasi terhadap efektifitas implementasi rencana stratejik pada madrasah aliyah di kabupaten sukabumi jawa barat. Skripsi: Universitas Pendidikan Indonesia

Lu, L., Lu, A. C. C., Gursoy, D., \& Neale, N. R. (2015). Work engagement, job satisfaction, and turnover intentions A comparison between supervisors and line-level employees. International Journal of Contemporary Hospitality Management, 28(4), 737-761. doi:10.1108/IJCHM-07-2014-0360

Nisfiannoor, M. (2013). Pendekatan statistika modern: aplikasi dengan software SPSS dan Eviews. Jakarta: Penerbit Universitas Trisakti

PojokJabar.com. (2018). Pengorbanan guru sekolah inklusi sdn bojongherang, ikhlas tak digaji, inisiatif jual ikan asin. https://cianjur.pojoksatu.id/baca/pengorbanan-gurusekolah-inklusi-sdn-bojongherang-ikhlas-tak-digaji-inisiatif-jual-ikan-asin

Prastadila, P. \& Paramita, P. P. (2013). Hubungan antara emotional intelligence dengan self efficacy guru yang mengajar di sekolah inklusi tingkat dasar. Jurnal Psikologi Pendidikan dan Perkembangan, 2(1), 35-45. https://www.google.com/url?sa=t\&rct=j\&q=\&esrc=s\&source=web\&cd=\&ved=2ahU KEwjdlr-

GwuTtAhXC8XMBHfaCAfgQFjAAegQIARAC\&url=http\%3A\%2F\%2Fjournal.una ir.ac.id\%2FfilerPDF\%2F110911165_Ringkasan.pdf\&usg=AOvVaw1vMLcMhebDC lrvxaxDfZk4

Rombot, O. (2017). Pendidikan inklusi. https://pgsd.binus.ac.id/2017/04/10/ pendidikan-inklusi/

Schaufeli, W. B., Salanova, M., González-Romá, V., \& Bakker, A. B. (2002). The measurement of engagement and burnout: a two sample confirmatory factor analytic approach. Journal of Happiness Studies, 3, 71-92. https://www.google.com/url?sa=t\&rct=j\&q=\&esrc=s\&source=web\&cd=\&cad=rja\&u act=8\&ved=2ahUKEwj_hKe2wuTtAhUhIbcAHR8YBAcQFjAAegQIAxAC\&url=ht tps\%3A\%2F\%2Fwww.wilmarschaufeli.nl\%2Fpublications\%2FSchaufeli\%2F178.pd f\&usg=AOvVaw1JwcTIZp0vjhwaKldZAEdy

Simbula. S., Guglielmi, D., \& Schaufeli, W. B. (2011). A three-wave study of job resources, self- efficacy, and work engagement among Italian schoolteachers. European Journal of Work and Organizational Psychology, 20(3), 285-304. doi: 10.1080/13594320903513916 
Sugiyono. (2017). Statistik untuk penelitian. Bandung: Alfabeta

Sulistyadi, H. K. (2014). Implementasi kebijakan penyelenggaraan layanan pendidikan inklusif di kabupaten sidoarjo. Kebijakan dan Manajemen Publik, 2(1), 1-10. https://www.google.com/url?sa=t\&rct=j\&q=\&esrc=s\&source=web\&cd=\&cad=rja\&u act $=8 \& v e d=2$ ahUKEwj61JGZw-

TtAhXN63MBHayjCrYQFjAAegQIARAC\&url=http\%3A\%2F\%2Fjournal.unair.ac.i $\mathrm{d} \% 2$ Fdownload-fullpaperskmp08e4cbae56full.pdf\&usg=AOvVaw2IJwcpWaH69stcUcizsxKJ

TribunJogja. (2018). Tak ada guru pendamping khusus di sekolah inklusi, kegiatan belajar ABK terhambat. https://jogja.tribunnews.com/2018/08/06/tak-ada-guru- pendampingkhusus-di-sekolah-inklusi-kegiatan-belajar-abk-terhambat?page $=1$ 